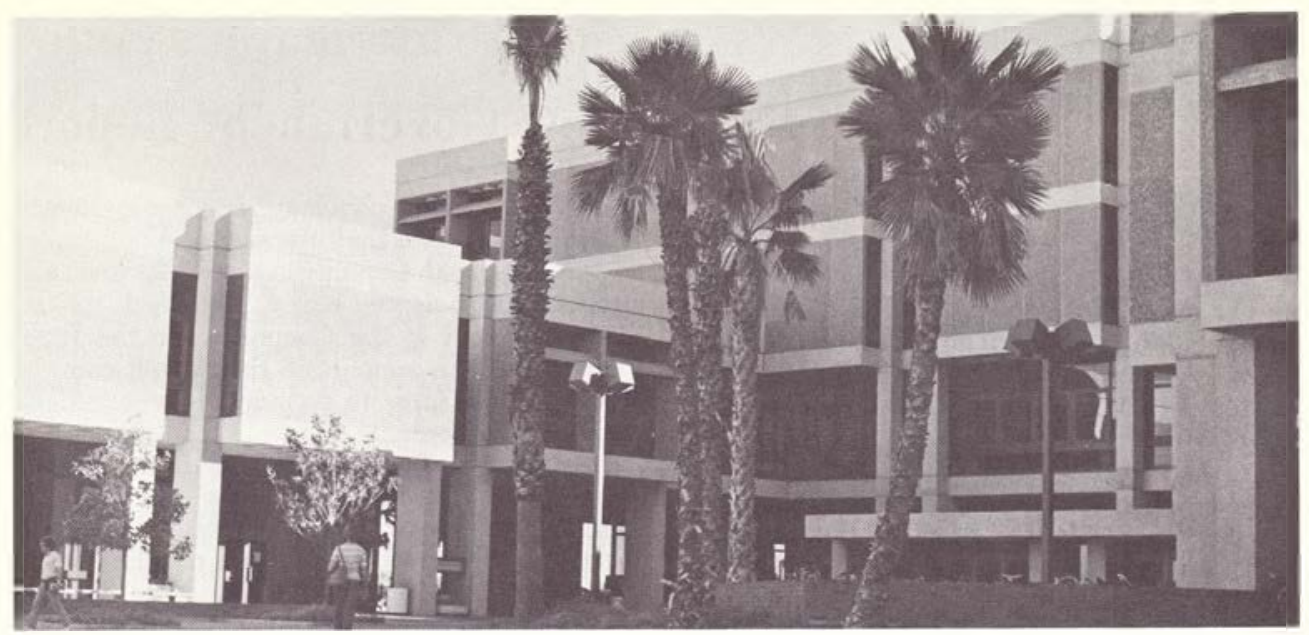

Univ. of Arizona Library exterior (above) and interior (below).

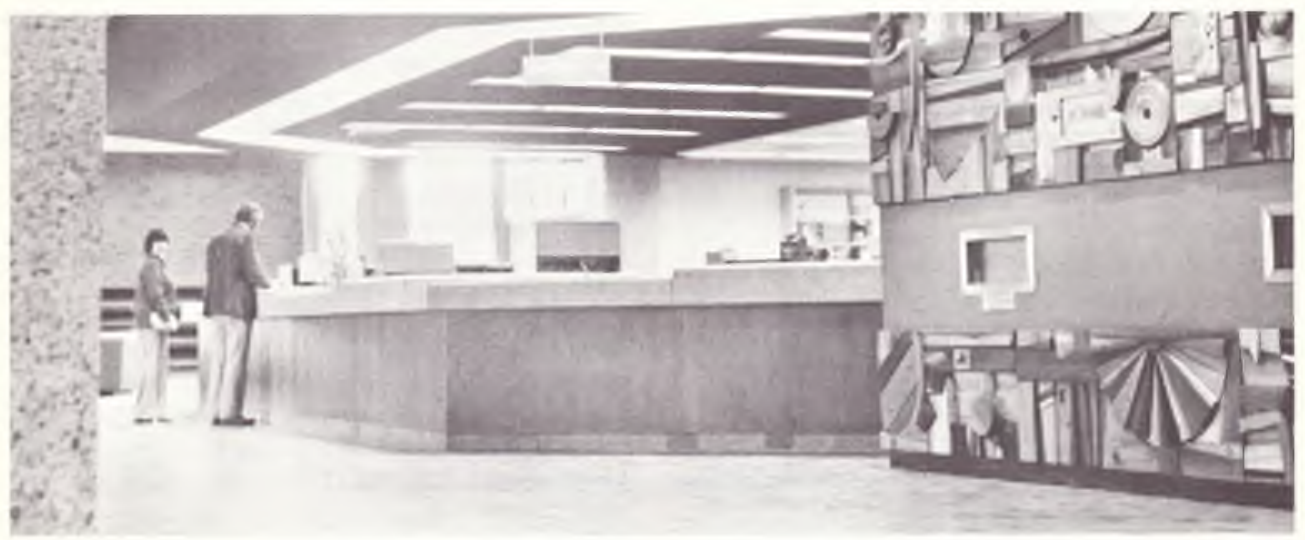

photos by Friedman and Jobusch

\title{
ACRL Internship Project Extended
}

The Association of College and Research Libraries is pleased to announce the extension of a $\$ 350,000$ grant from the Andrew W. Mellon Foundation to fund a fourth year of the Academic Library Internship Program for Administrators of Predominantly Black College and University Libraries.

The project is intended to accelerate the development of the management ability of librarians in black colleges and universities by providing them with experience in the administration of strong and progressive academic libraries.

The interns study library administrative methods, exchange ideas and discuss problems with staff members in the host institution, and participate in the day-to-day management of the host library. The program is designed for librarians in black colleges who have potential as administrators, based upon experience and/ or performance in library school.

For the $1977 / 78$ academic year, four interns will be placed in selected academic libraries for a period of six months, from January to June 1978. The Mellon Foundation grant provides salaries, benefits, and approved expenses for the interns.

ACRL is now accepting applications, both from prospective interns and from prospective host institutions, for the fourth year of the project. Application forms and additional information are available from the project director, Casper L. Jordan, University Librarian, Trevor Arnett Library, Atlanta University, Atlanta, GA 30314. 